\title{
Levantamento sorológico de quatro micoses profundas no Estado do Amazonas, Brasil (*)
}

\author{
Wai Yin Mok (**) \\ C. Haroldo L. Ayres ("*) \\ Shirley McMillen ( ${ }^{* * \hbar}$ )
}

\section{Resumo}

Realizou-se um levantamento sorológico gle quatro micoses profundas em 499 pacientes internados no único sanatório para tuberculosos em Manaus, Amazonas, e em 545 adultos clinicamente normais selecionados de 3 cidades, 6 seringais e 6 vilas de indios Ticunas, todos no Amazonas. Encontraramse, pela reação de imunodifusão, 18 casos $(3,6 \%)$ de micoses nos soros dos pacientes tuberculosos, sendo 8 de paracoccidioidomicose, 7 de aspergilose, 2 de histoplasmose e 1 de esporotricose. Sete dos oito pacientes reagentes à paracoccidioidina eram mulheres. Não foram demonstradas as presenças de anticorpos à histoplasmina, aspergilina e esporotriquina em nenhum dos soros dos indivíduos assintomáticos

\section{INTRODUÇÃo}

A infecção pulmonar, como uma manifestação primária de dơença, está reconhecida em muitas micoses profundas. Os aspectos clínicos e roentgenográficos das micoses respiratórias podem mimetizar os da tuberculose pulmonar. As duas micoses mais freqüentemente associadas com a tuberculose, são a histoplasmose e a aspergilose (Furcolow et al., 1962; Sinski, 1975) .

No Brasil, excetuando-se a malária, a tuberculose é a doença com maior índice de morbidez (Fundação SESP, 1977). A Amazônia é uma região endêmica para tuberculose, histoplasmose, esporotricose e paracoccidioidomicose (Tesh \& Marques, 1966; Fonseca et al., 1973; Bouilos et al., 1975; Rezende \& Souza, 1975; Mok \& Fava Netto, 1978). O estudo aqui apresentado é constituído de um levantamento sorológico de quatro micoses sistêmicas em individuos com e sem sintomas compativeis com os de tuberculose no Amazonas. As mico. ses pesquisadas foram: a histoplasmose, a esporotricose, a aspergilose e a paracoccidioidomicose.

\section{MATERIAL E MÉTODOS}

Os indivíduos sintomáticos eram pacientes internados no único sanatório para tuberculosos em Manaus. Todos os pacientes tinham sintormas clínicos e roentgenográficos sugestivos de tuberculose pulmonar e não apresentavam história de micose profunda. Um ou mais dos escarros, coletados de cada paciente em três dias consecutivos antes de internação, foram positivos para bacilos alcool-ácido resistentes. De setembro de 1976 a fevereiro de 1977, foram examinado só os pacientes admitidos em semanas alternadas. Com base nos resultados deste levantamento preliminar, decidiu-se examinar todos os pacientes admitidos ao hospital até o agosto de 1977. Foram coletados $10 \mathrm{ml}$ de sangue de cada dos pacientes na primeira semana de hospitalização.

Os indíviduos assintomáticos procederam de população urbana de comunidades rurais e de habitantes de várias vilas no interior do Amazonas. As áreas de estudo foram: as cidades de Barcelos (pop. 1.300) ${ }^{\mathrm{a}}$, Manacapuru (pop. 9.300) ${ }^{\mathrm{a}}$, Codajás (pop. 3.300$)^{\mathrm{a}} ; 6$ vilas de índios Ticunas, variando de 35 a 400 habi. tantes $^{\mathrm{b}}$ em cada, no rio lçá; e 6 seringais, com aproximadamente 15 familias $^{c} \mathrm{em}$ cada, no rio Purus (Fig. 1).

Em Barcelos, Manacapuru e Codajás os participantes eram funcionários de hospital e habitantes que voluntariamente vieram atendendo do chamado para o diagnóstico de ma-

( ) - Trabalho realizado com recursos do CNPq e da Secretaria de Saúde do Estado do Amazonas

() - Instituto Nacional de Pesquisas da Amazônia, Manaus.

(*) - Cook Country Hospital, Hektoen Institute, Chicago, U.S.A. 
lária e filariose. Nas vilas dos Ticunas e nos seringais, as visitas dos pesquisadores foram combinadas para que a maioria dos moradores pudessem participar no estudo. Fez-se rotineiramente o exame-físico para todos os participantes e coletaram-se $10 \mathrm{ml}$ de sangue de cada um deles. Os soros foram conservados a $4^{\circ} \mathrm{C}$ com mertiolate $(1: 10.000)$ até uso. Baseado no conhecimento atual da epidemiologia das quatro micoses sob investigação e devido a quantidade de antígenos disponíveis, selecionamos só os soros dos adultos com mais de 30 anos clínicamente normais.

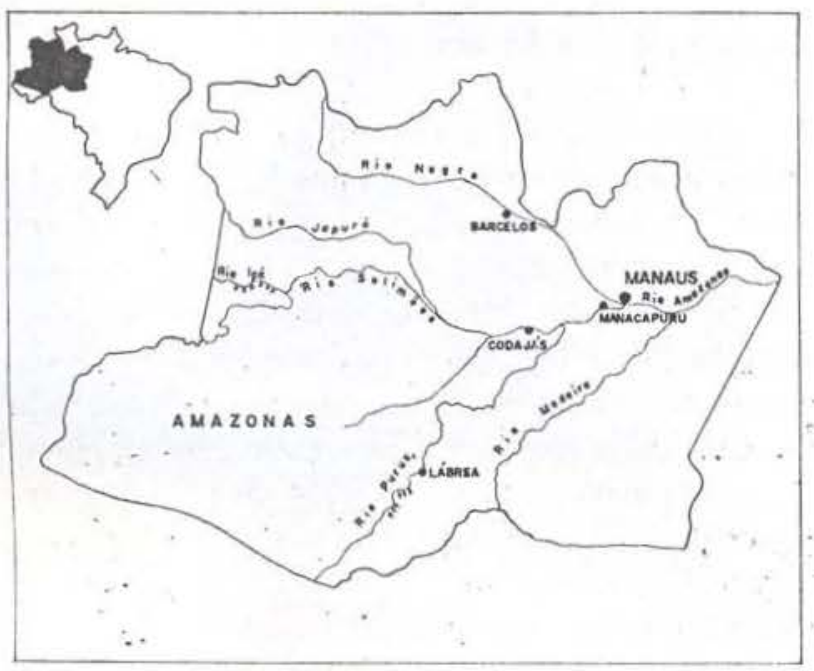

Fig. 1-Áreas de estudo: $\uparrow=$ seringal (Capacini, Cassiana, Nova Brasil, Iqualdade, Abonini, Manoifania) $\boldsymbol{A}=$, vila dos Ticunas (Boca do Moinho, Cuiaua, Içá Cuera, rio Jaurapa, Vila Betânia, Nova Itália).

Fez-se a reação de imunodifusão no agargel com os soros. Foram perfurado seis cavidades, cada uma de $6 \mathrm{~mm}$ em diâmetro, distanciadas $6 \mathrm{~mm}$ uma da outra e $4 \mathrm{~mm}$ de uma cavidade central igual, num gel de agarose à $1,5 \%$ (Merck) em solução salina à $0,85 \%$. Colocou-se $0,1 \mathrm{ml}$ de soro em cada cavidade periférica e $0,1 \mathrm{ml}$ de antígeno na cavidade central. Três antígenos de filtrados de culturas foram preparados de Histoplasma capsulatum, Sporothrix schenckii e Aspergillus fumigatus. A fase micelial destes fungos foi cultivada num meio de glucose-asparagina (Smith et al., 1948) a $25^{\circ} \mathrm{C}$. No término de 3 meses foi adicionado às culturas o mertiolate na concentraçăo final de 1:10,000. O líquido da cultura foi separado por centrifugação, dializado com água destilada, liofilizado e guardado em vácuo. Mais um antígeno foi usado na imunodifusão dos soros dos pacientes tuberculosos, i.e. a paracoccidioidina, preparada da fase leveduriforme de Paracoccidioides brasiliensis (Restrepo, 1966). Como controles usaram-se os soros dos casos humanos positivos comprovados pela cultura. Os soros que reagiram positivamente com a histoplasmina ou paracoccidioidina foram adicionalmente analizados pela reação de fixação de complemento. Os antígenos usâdos foram: paracoccidioidina. histoplasmina e uma preparação de celular leveduriforme de $H$. capsulatum.

\section{Resultados}

Examinaram-se 499 pacientes, os quais representavam $61,8 \%$ dos pacientes hospitalizados no sanatório na época de estudo. Havia 251 homens e 248 mulheers, de 13 a 71 anos. Todas eram originários da Amazônia. Mostrouse a presença de anticorpos aos antígenos micóticos nos soros de 18 pacientes $(3,6 \%)$ : 8 à paracoccidioidina $(1,6 \%), 7$ à aspergilina $(1,4 \%), 2$ à histoplasmina $(0,4 \%)$ e 1 à esporotriquina $(0,2 \%)$. A tabela 1 mostra os resultados da fixação de complemento dos soros positivos na imunodifusão. Os soros positivos à paracoccidioidina provieram de 1 homem e 7 mulheres. Não se isolou nenhum fungo patogênico no meio de Mycosel e Sabouraud dos escarros dos pacientes sorologicamente positivos.

Foram testado os soros dos 545 participantes assintomáticos. Havia 176 habitantes de Barcelos, 84 de Manacapuru, 78 de Codajás, 90 de seringais e 117 Ticunas, dando um total de 259 homens e 286 mulheres, e uma idade média de 39. Não foram demonstrados anticorpos à histoplasmina, aspergilina e esporotriquina em nenhum dos soros destes indivíduos assintomáticos.

\section{DISCUSSÃo}

Este estudo foi o primeiro levantamento sorológico sobre as micoses profundas em pessoas com e sem sintomas compativeis com os da tuberculose, no Amazonas. As pessoas sin- 
tomáticas poderiam ser consideradas como demograficamente representativas dos tuberculosos no Estado, sendo que o sanatório é o único no Estado. A seleção dos habitantes urbanos, rurais e indigenas de setores geograficamente separados foi uma tentativa de examinar uma população tão heterogênea $€$ representativa como permitido pelas condições das excursões.

A eficácia da reação de imunodifusão como um instrumento diagnóstico e epidemiológico de micoses depende da sensibilidade e especificidade da mesma. Para o diagnóstico das quatro micoses sob investigação, a sensibilidade da reação variou de $74 \%$ a $94 \%$, e a especificidade aproximou-se a $100 \%$ (Restrepo, 1966; Restrepo \& Moncada, 1970; Blumer et al., 1973; Gerber \& Jones, 1973). Nos estudos prévios, foi demonstrado, pelas reações intradérmicas, a endemicidade das infecções subclínicas e benignas da paracoccidioidomicose, histoplasmose e esporotricose nas diversas populaçōes normais no Amazonas (Fonseca et al., 1973; Mok \& Fava Netto, 1978). O fato de não termos demonstrado a presença de anticorpos nos soros dos 545 adultos clinicamente normais apenas indica a falta de suficiente sensibilização humoral nestas pessoas aos antígenos em estudo, ou a outros antígenos que produzissem reações cruzadas. A evidência sorológica de micoses só nos pacientes tuberculosos sugere a presença de infecções mista. Para comprová-las seria necessário, no entanto, a demonstração do agente etiológico através de culturas, o que não se conseguiu. O achado de $3,6 \%$ de micoses nos tuberculosos pode ser tomado como um índice de micoses pulmonares presuntivas. Figurativamente, este índice representa o pico de "medical mycological iceberg" (Ajello, 1970) que consiste de todos os casos não diagnosticados nos pacientes com sintompatologia pulmonar na região. Os resultados deste estudo justificam um extensivo diagnóstico diferencial para as micoses respiratórias nos pacientes pulmonares, ambulatórios ou hospitalizados.

Moraes \& Ferreira (1967) numa revisão sobre as micoses na Amazônia, citaram a esporotricose subcutânea como uma das misoses profundas mais prevalentes na regiäo. Eles também anotaram a incidência extremamente
TABELA 1 - Resultado das reações de fixação de complemento.

\begin{tabular}{ccccc}
\hline $\begin{array}{c}\text { Pacien. } \\
\text { te }\end{array}$ & $\begin{array}{c}\text { Sôros com } \\
\text { anticorpos } \\
\text { à }\end{array}$ & para. & histo. & $\begin{array}{c}\text { levaduras } \\
\text { de H. cap. } \\
\text { sulatum }\end{array}$ \\
\hline & para. & $1: 64$ & $(-)$ & $(-)$ \\
1 & $n$ & $1: 32$ & $(-)$ & $(-)$ \\
2 & $n$ & $1: 8$ & $(-)$ & $(-)$ \\
3 & $n$ & NF & NF & NF \\
4 & $n$ & NF & NF & NF \\
5 & $n$ & AC & AC & AC \\
6 & $(-)$ & $(-)$ & $(-)$ \\
7 & $n$ & $(-)$ & $(-)$ & $(-)$ \\
8 & $n$ & $1: 32$ & $(-)$ & $1: 32$ \\
16 & histo. & $(-)$ & $(-)$ & $(-)$ \\
17 & $n$ & $(-)$ & & \\
\hline
\end{tabular}

baixa da histoplasmose e paracoccidioidomicose. De interesse, deste estudo, é que entre os 18 casos presuntivos, a paracoccidioidomicose e aspergilose excederam as outras duas micoses.

\section{AGRADECIMENTOS}

Agradecemos aos Dr. O. Said que permitiu seu acesso do Sanatório Adriano Jorge, Dr. H. V. Dourado que providenciou algumas das excursões, e Dra. A. Restrepo M. que forneceu a paracoccidioidina e os resultados da reação de fixação de complemento.

\section{SUMMARY}

A serologic survey on systemic mycoses was done on 499 hospitalized patientes in the single state tuberculosis sanatorium in Manaus, Amazonas, and on 545 clinically normal adults selected from 3 cities, 6 rubber planatation communities and 6 Ticuna Indian villages in the state of Amazonas. Eighteen $(3.6 \%)$ sera from the tuberculosis patients were positive in the immunodiffusion test: 8 against paracoccidioidin, 7 against aspergillin, 2 against histoplasmin and 1 against sporotrichin. Seven of the eight tuberculosis patients with precipitin antibodies to paracoccidioidin were female. Antibodies to histoplasmin, aspergillin and sporotrichin were not detected in any of the sera from the asymptomatic individuals. 


\section{BibLIOGRAFLA}

AJELLO, L.

1970 - The medical mycological iceberg. Proc. Internat. Symp. on Mycoses, PAHO Sci. Publ., 205: 3-12.

Blumer, S.C.; Kaufman, L.; Kaplan, W.; Mclaughlin, D.W. \& KRAFT, D.E.

1973 - Comparative evaluation of five serolo. gical methods for the diagnosis of sporotrichosis. Appl. Microbiol., 26:4-8.

Boulos, M.; Labonies Filho, N.; Draibe, S.E.; Pinto, W.P.; LANCERotte, I.; SHIROMA, M.; \& FAVA NetTo, C.

1975 - Inquérito imuno-alérgico com paracoccidioidina e histoplasmina nas localidades de Itupiranga e de São João do Araguaia - Pará, Anais do XI Cong. Soc. Bras. Med. Trop.

Fonseca, O.J.M.; LACaz, C.S. \& Machado, P.A.

1973 - Inquérito imuno-alérgico na Amazônia. Resultados preliminares. Rev. Inst. Med. Trop. São Paulo, 15 : 359-363.

FUNDAÇÃo SESP, MINISTÉRIo da SAÚdE 1972 - 1977 Boletim Epidemiológico, V-IX.

FUrcolow, M.L.; SCHUberT, J.; TOSH, F.E.; DOTO, I.L. \& LYNCH, JR., H.J.

1962 - Serologic evidence of histoplasmosis in sanatoriums in the U.S. J. A. M. A., $180: 109-114$

GERBER, J.D. \& JONES, R.D.

1973 - Immunologic significance of aspergillin antigens of six species of Aspergillus in the serodiagnosis of aspergillosis, Am. Rev. Resp. Dis., 108 : 1124-1129.
MoK, W.Y. \& FAvA Netto, C.

1978 - Paracoccidioidin and histoplasmin sensitivity in Coari (State of Amazonas), Brazil. Am. J. Trop. Med. Hyg., 27: 808-814.

MorAes, M.A.P. \& FerreirA, J.L.S.

1967 - Micoses superficiais e profundas na Amazônia. Atas do Simpósio sobre a Biota Amazônica (Patologia) 6:189-202.

RESTREPO, A.

1966 - La prueba de inmunodifusion en el diagnóstico de la paracoccidioidomicosis. Sabouraudia, $4: 223-230$.

Restrepo M., A. \& Moncada F., L.H.

1970 - Sero'ogic procedures in the diagnosis of paracoccidioidomycosis. Proc. Internat. Symp. on Mycoses, PAHO Sci. Publ., $205: 101-110$.

REZENDE, M.B. \& SOUZA, O.S.

1975 - Estudo epidemiológico com a reação intradermica com a histoplasmina, em Belém-Pará. Anais do XI Cong. Soc. Bras. Med, Trop.

SINSKI, J.T.

1975 - The epidemiology of aspergillosis. The Epidemiology of Human Mycotic Diseases. Y. Al-Doory. ed., Charles C. Thomas Publishing Co., Springfield, p. 210-226.

SMTTH, C.E.; WhITING, E.G.; BAKer, E.E.; Rosenberger, H.G.; BEARD, R.R. \& SAITO, M.T.

1948 - The use of coccidioidin. Am. Rev. Tuberc., $57: 330-360$.

TESH, R.B. \& MARqUeS, R.J.

1966 - Histoplasmin sensitivity in Brazil Am. J. Trop. Med. Hyg., $15: 359-363$.

(Aceito para publicação em 10/01/79) 